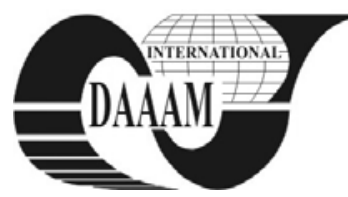

Annals of DAAAM for 2011 \& Proceedings of the 22nd International DAAAM Symposium, Volume 22, No. 1, ISSN $1726-9679$ ISBN 978-3-901509-83-4, Editor B. Katalinic, Published by DAAAM International, Vienna, Austria, EU, 2011 Make Harmony between Technology and Nature, and Your Mind will Fly Free as a Bird Annals \& Proceedings of DAAAM International 2011

\title{
THE EVALUATION OF AUDIOMETRIC RESULT
}

\section{DOLINAY, V[iliam]; VASEK, V[ladimir] \& PIVNICKOVA, L[ucie]}

\begin{abstract}
The aim of this work is to prepare the system, which removes redundant and repetitive tasks in the implementation of certain types of hearing function examinations. Proposed system minimize time needed to examine patient and also get ready the full digitization of the results. The obtained database can lately become the base for subsequent processing such as artificial intelligence expert systems which can expand diagnostic possibilities. In cooperation with physicians, the above mentioned system began to be developed, however all tools still need to be fully implemented and tested. Several basic features have already been implemented into the Fowler system which became to find its place in seveal doctor's surgery.
\end{abstract}

Key words: audiometry, examination, hearing lost, ORL

\section{INTRODUCTION}

There is still a large group of medical examinations with explicit steps, which has no computer support even the algorithms to perform them have fixed structure. For example, the calculation of hearing loss based on Fowler method (Lejska, 2006) is often carried out using a hand calculator, printed table and pencil. Despite the fact that in this calculation are used only basic mathematical operations from a technical perspective, one might say that it is not too complicated, but the amount of input data it make it in manual calculation quite time-consuming and highly prone to the occurrence of calculation errors. A skilled nurse for this calculation will need several minutes while the software is designed to properly evaluate the measurements in the real time.

The above mentioned example is just one option for possible improvement. Another area of optimization and efficiency improvements are seen in archival data obtained during examinations. In current practice, examination results are stored in various ways, mostly in the form of printed or even hand-generated charts, graphs, and plain text. These greatly reduce the possibility of re-use of data for mutual comparison, analysis, or as a data source in the direct evaluation of artificial intelligence.

Presented work also aims to way, improving the current situation, where doctors are forced to constantly rewrite results into the various forms, software tools, perform additional calculation and so on. However, this work is not focused to replacing these specialized software tools but complement them and rather to provide the ability to easily export and import measured date into them, without rewriting which is the most significant disadvantage of current situation.

The above mentioned considerably lengthen the time needed to perform the tests, thus increasing the time patients need to spend in the doctor office and everything is logically reflected in the final price of such examination. Respectively, in the current system, the price action from the given by a physician point of view is fixed, but as far as possible we will reduce the time needed to process examination, it at least makes doctors work easier, or enable to treat more patients. From the market perspective, it reduces the cost of the examination.
To comply with the idea as close as possible, at every stage of the solution of this task requires close cooperation with doctors and paramedical staff.

\section{TONE AUDIOMETRY}

The work is focused on variety of examination; however the pure tone audiometry is one of the frequently performed and significant for selected targets (Katz, 2001)

Pure tone audiometry is the key hearing test used to identify hearing threshold levels of an individual, enabling determination of the degree, type and configuration of a hearing loss. Thus, provides the basis for diagnosis and management. Pure tone audiometry is a subjective, behavioral measurement of hearing threshold, as it relies on patient response to pure tone stimuli. Therefore, pure tone audiometry is used on adults and children old enough to cooperate with the test procedure.

\subsection{Improvements}

The aim for the improvement of this examination was to remove all the rewriting and hand calculations. It contained the following tasks:

- Implementation of the connection to the PC provides possibility to obtain online access to measured data.

- Preparation of printing and exports into graphic file formats.

- Proposal of algorithms, development and subsequent implementation of the calculation of hearing loss according to Fowler, the mean rate of loss of speech, etc.,

- Implementation of communication between computers within a local network - usually a physician and nurse are working on different computers and it is appropriate to share information.

- Implementation of interconnection with the most commonly used specialized programs (third-party products) and by obtaining data directly from the already existing databases, as well as the possibility of copying the final results to patient day records.

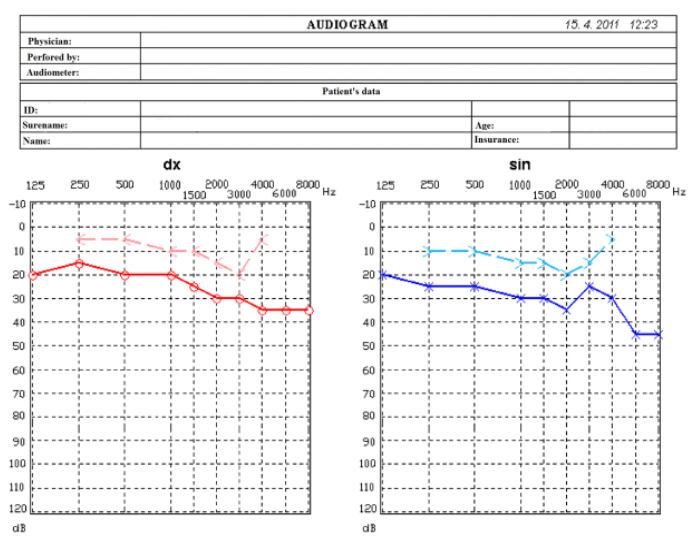

Fig. 1. Audiogram from the Fowler system 
The figure above shows the result of tone audiometry - air and bone conduction of person with mildsensorineural hearing loss. The chart is drawn by the proposed system "Fowler". The curves are built dynamically due to direct communication with the hardware, during the examination.

\section{DATE EVALUATION}

As mentioned earlier, in paragraph 2.1, proposed system, called "Fowler", implements steps improving all key parts of audiometrical examination. First, the communication with the measuring hardware was developed, followed with various evaluations for the visualization. The saving and exporting of the result were prepared as well. All those parts were implemented in the form of software modules, forming Fowler system.

The main features implemented in Fowler's modules for evaluating the audiometrical result are described below:

\subsection{Comparison of audiometric results}

The audiometric curves can be compared graphically and numerically, according to previous investigations. See Fig. 2.

This function is based on the requirement of physicians who tested the system and consider it an important tool in the overall view of audiometric examination in individual patients during treatment.

\subsection{Measurements with the comparison}

Module is based on the same principles as the results comparison. A measurement of the new records has on the background curve of the previous examination (if available).

This function is based on the requirement of audiometric nurses who tested the system and considered it an important in carrying out repeated audiometric examinations.

\subsection{Calculations and evaluation of results}

As mentioned in previous paragraphs, in the case of audiometric examination, the system automatically calculates the hearing loss according to Fowler and the average loss for a given frequency. These values, along with the information about the patient's age, which are implicit, allow us some additional criteria to calculate. Currently implemented are the following criteria:

- Classification of the hearing loss by age.

- Classification of the hearing loss according to the decree of The Ministry of Labor and Social Affairs of Czech Republic.

- Determination of the grade of hearing impairment according to the WHO (World Health Organization)

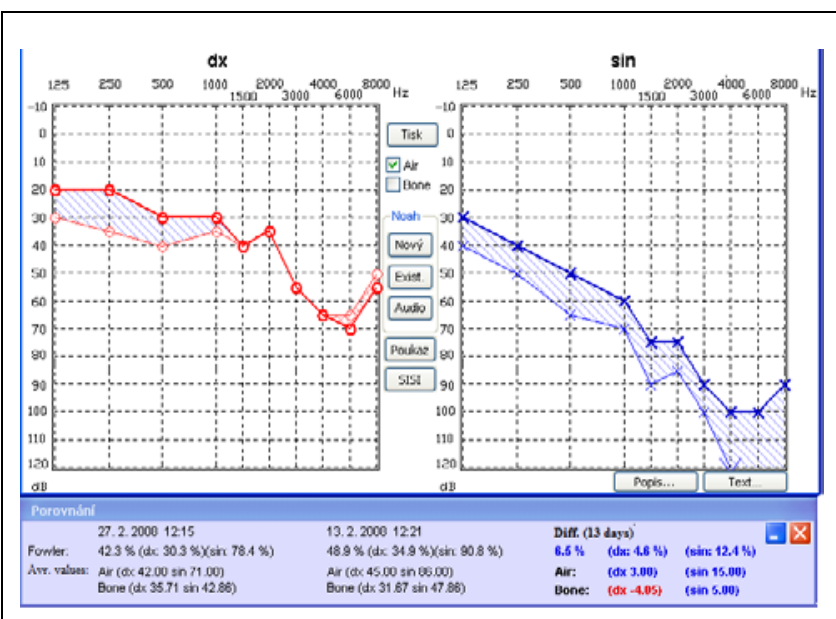

Fig. 2. Comparison of audiometric results

\begin{tabular}{|l|l|l|}
\hline $\begin{array}{l}\text { Grade of } \\
\text { impairment }\end{array}$ & $\begin{array}{l}\text { Corresponding } \\
\text { audiometric ISO value }\end{array}$ & Performance \\
\hline $\begin{array}{l}0 \text { - No } \\
\text { impairment }\end{array}$ & $\begin{array}{l}\text { 25 dB or better } \\
\text { (better ear) }\end{array}$ & $\begin{array}{l}\text { No or very slight hearing } \\
\text { problems. Able to hear } \\
\text { whispers. }\end{array}$ \\
\hline $\begin{array}{l}1 \text { - Slight } \\
\text { impairment }\end{array}$ & $\begin{array}{l}26-40 \mathrm{~dB} \\
\text { (better ear) }\end{array}$ & $\begin{array}{l}\text { Able to hear and repeat } \\
\text { words spoken in normal } \\
\text { voice at } 1 \text { metre. }\end{array}$ \\
\hline $\begin{array}{l}2 \text { - } \\
\text { impairment }\end{array}$ & $\begin{array}{l}41-60 \mathrm{~dB} \\
\text { (better ear) }\end{array}$ & $\begin{array}{l}\text { Able to hear and repeat } \\
\text { words spoken in raised } \\
\text { voice at 1 metre. }\end{array}$ \\
\hline $\begin{array}{l}3 \text { - Severe } \\
\text { impairment }\end{array}$ & $\begin{array}{l}61-80 \mathrm{~dB} \\
\text { (better ear) }\end{array}$ & $\begin{array}{l}\text { Able to hear some words } \\
\text { when shouted into better } \\
\text { ear. }\end{array}$ \\
\hline $\begin{array}{l}4 \text { - Profound } \\
\text { impairment } \\
\text { including } \\
\text { deafness }\end{array}$ & $\begin{array}{l}\text { 81 dB or greater } \\
\text { (better ear) }\end{array}$ & $\begin{array}{l}\text { Unable to hear and } \\
\text { understand even a } \\
\text { shouted voice. }\end{array}$ \\
\hline
\end{tabular}

Tab. 1. Grades of hearing impairment (WHO, 2011)

World Health Organization defines 5 grades of hearing impairments, see Tab. 1 . Grades 2, 3 and 4 are classified as disabling hearing impairment. The audiometric ISO values are averages of values at 500, 1000, 2000, and $4000 \mathrm{~Hz}$. System Fowler, which has all these information, in this case is responsible only for calculating averages value and select the appropriate grade and inform physician.

\section{CONCLUSION}

A system for evaluating the results of tone audiometry was prepared. The system implements a module for communication with the hardware, data storage procedures and tools for visual and numerical representation of evaluation results. Important for the practical use are especially the modules for the comparison of audiometric examination during the evaluation, or during the examination. The calculation functions of Fowler system implements the evaluations according to World Health Organization such as the decree of competent authorities. The system has been deployed for the practical tests in ORL specialist's offices. However, depending on the requirements of physicians, it will be certainly necessary to add additional functionality.

\section{ACKNOWLEDGEMENTS}

The work was supported by the Ministry of Education, Youth and Sports of the Czech Republic under the Research Plan No. MSM 7088352102 and by the European Regional Development Fund under the project CEBIA-Tech No. CZ.1.05/2.1.00/03.0089.

\section{REFERENCES}

Bingham, B. \& Hawke, M. (1991). Atlas of clinical otolaryngology, Mosby-Year Book; illustrated edition, ISBN 978-1556643156

INTERACOUSTICS. (2009). Audiometer hearing solution, Available from: http://www.interacoustics.com/com_en/, Accessed on: 2011-04-11

Katz, J. (2001). Handbook of Clinical Audiology. Lippincott Williams \& Wilkins; Fifth Edition edition. ISBN 9780683307658

Lejska, M. (1994). Introduction to Practical audiology and audiometry. Idvpz. Brno, ISBN 80-7013-178-0.

Levy, M. N., Koeppen, B. M., Stanton, B. A. \& Berne, R. M. (1998). Physiology, Mosby-Year Book; 4th edition, ISBN 978-0815109525

WHO. (2011). Grades of hearing impairment, Available from: http://www.who.int/pbd/deafness/hearing_impairment_grad es/en/index.html, Accessed on: 2011-04-12 